\title{
Adaptive Navigation Support: A Literature Review of Its Application and Implication in Learning Process
}

\author{
https://doi.org/10.3991/ijet.v14i16.10719 \\ Almed Hamzah ${ }^{(凶)}$ \\ Universitas Islam Indonesia, Yogyakarta, Indonesia \\ almed.hamzah@uii.ac.id \\ Kurniawan D. Irianto \\ TU Dresden, Dresden, Germany
}

\begin{abstract}
The use of technology has been widely used for many people in every aspect of life and become part of daily activities in recent years. One of technology application is in the learning and education process. Adaptive Navigation Support (ANS) is a method and part of a hypermedia study that can boost the performance of students by using the benefit of technology. With ANS, students are able to make the learning process more interesting as the learning material relatively corresponds to their knowledge and preferences. Furthermore, ANS can guide students in finding their paths and ways in hyperspace based on student requirements, goals, and characteristics. Therefore, ANS has caught many researcher's attention in their studies to improve student skills and performance in the learning process. Many papers, discussed in ANS, have been published over the last decade, however, no one has studied the ANS in a comprehensive way. This paper is a literature review in ANS and its application as well as its implication in the learning process. There are forty-nine papers as its source of analysis. Our findings show that the applications of ANS can be classified into four dimensions, such as platform, use case, impact, and process. These classifications are based on the study of ANS applications and implications over the last decade.
\end{abstract}

Keywords - Adaptive navigation support, learning application and implication, content analysis

\section{Introduction}

With the advanced of technology in recent years, the learning paradigm has moved from traditional (i.e. paper-based and face-to-face learning) to an electronic environment. The term electronic environment refers to the use of technology and interactive media, for instance, the internet, films, radio, television program, etc. Adaptive Navigation Support (ANS) is a part of Adaptive Hypermedia (AH) studies that exploit technology to improve student skills and performances in the learning process. Moreover, ANS can become an alternative to the traditional "one-size-fits-all" approach in the hypermedia development systems [1]. 
In the earlier of web-based technology, the Web has been provided an interesting platform for adaptive hypermedia applications. In fact, it has demonstrated the power of ANS in several applications. However, an interactive web-based application for ANS is not enough. With the development of mobile technology, people tend to do all their activities in gadgets (i.e. smartphone, tablet, and netbook). As a result, the mobile platform has become a common platform. Thus, the implementation of ANS should also consider these emerging contexts. ANS aims to give a better experience to mobile users through mobile-platform applications. The users could use the applications based on their requirements and preferences. ANS can, as well, identify and make adjustments, based on the characteristics of users, such as user objectives, preferences, knowledge [2], and capability [3]. With a such adaptation, it is expected that students' learning experiences and performances will increase significantly [4].

ANS has, widely, been used in academic environments, particularly in schools or colleges to improve student's experiences in learning processes by using e-learning application. With this approach, students will share their learning characteristics with the system [5] that in turn allows them to manage their learning performance based on their own learning objective and current knowledge [6].

However, a literature study is needed for mapping the implementation of ANS in a learning process. This paper presents ANS and its implementation for students in learning process. In addition, our goal is to give a bigger picture of ANS implementation to researchers or e-learning system developers so that their applications could be effective and efficient for the users, especially students, in learning process.

The rest of this paper is organized as follows: firstly, we describe the method in Section II. Secondly, we present the result and discussion in Section III. Finally, we end the paper by presenting a conclusion in Section IV.

\section{$2 \quad$ Method}

\subsection{Scope and material}

The material for this paper is papers discussed ANS. We study the papers published over the last decade. The papers are from the ScienceDirect database with the criteria as follows:

- Keyword: "Adaptive Navigation Support in Learning"

- Papers written only in journals

- Published in period between 2010-2019

Based on these criteria, we found 203 papers. Then, these papers were selected to get more relevant papers to our research. The selection was done by seeing the content of paper through the abstract that is significantly related to our criteria. The criteria are:

- Papers are related to our topic

- Papers discuss, directly, about adaptive navigation support

- Papers are not a literature study 
From this process, 49 papers were selected to be analyzed further. The distribution of papers in terms of year is depicted in Figure 1.

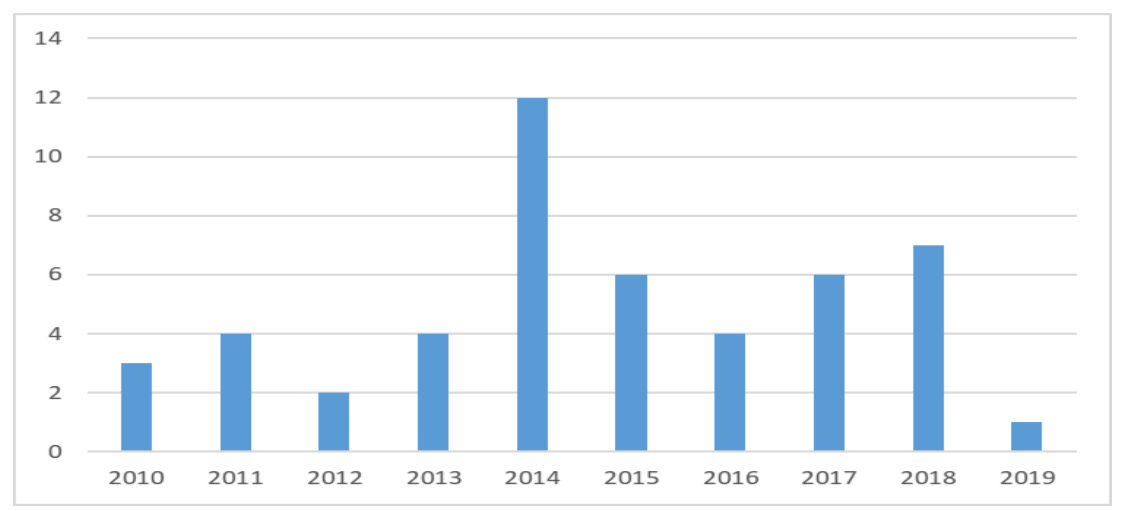

Fig. 1. Paper distribution

\subsection{Steps of analysis}

In order to optimize the results in our research, we used a content analysis method for hypermedia. It is an important method for analyzing the content of documents [7]. In this case, the documents refer to all kinds of media, either electronic or non-electronic media. The electronic media, such as internet, radio and television programs, films, audio speeches, are more commonly used than non-electronic media, for example newspapers, reports, magazines, letters, books, in recent years.

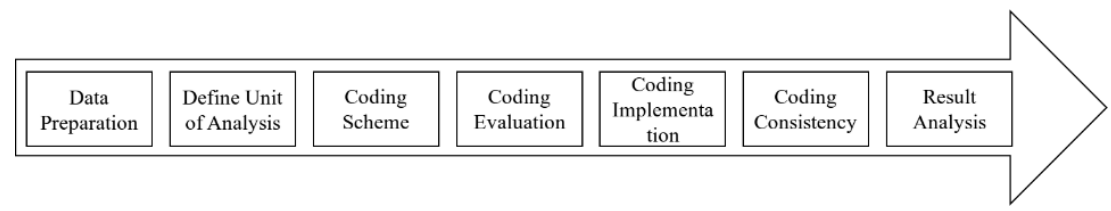

Fig. 2. Steps of Analysis

The analysis consists of two main steps, for instance, wordcloud and qualitative data analysis. Wordcloud analysis is used to get bird's-eye view of our research topic. Meanwhile, qualitative data analysis is for identifying in depth and classifying our research topic into several themes derived from wordcloud analysis.

Qualitative data analysis is done through the coding process. In this study, the code (i.e. theme or important term related to the research) was obtained during the literature review process which became the material of the research. The coding steps consist of several processes [8] as shown in Figure 2, namely:

- Preparing data

- Determining unit of analysis

- Compiling coding and categorizing schemes 
- Testing coding scheme

- Implementation of the coding process for the entire data

- Testing the consistency of coding

- Analysis of results and drawing conclusions

- Compiling report findings

Data preparation includes paper searching in the ScienceDirect database. The chosen unit of analysis in this research is the adaptive navigation support that is used in the learning process. The next step is coding processing which starts with the code selections that is relevant to our research topic. Finally, the code is analyzed until the conclusion has been reached.

\section{$3 \quad$ Result and Discussion}

This part is divided into two sections describing analysis result from wordcloud analysis and qualitative data analysis. Wordcloud analysis is utilized in order to gain bird's eye-view of the topic whereas qualitative data analysis aims to gain a more detailed perspective. As depicted in Figure 3, some key words have emerged in various size. The size of the words represents its frequency. The bigger of the size the more frequent it showed up in the literatures. In contrast, the smaller of the size shows that it is less frequent in the literatures.

Among the most frequent words are learning, students, study, design, group, results. Among the less frequent words are scores, motivation, work, data, tools, and devices. In addition, there are also words in between such as mobile, cognitive, paper, and game.

Based on its size on the Figure 3, the key words then can be categorized into three groups. First, group with the most frequent words. It shows that the discussion is emphasized on the learning process whereas in group of the less frequent words focus on the learning result. Moreover, the group in between focus on the methodology or learning paradigm that can bridge the learning process and technology. 


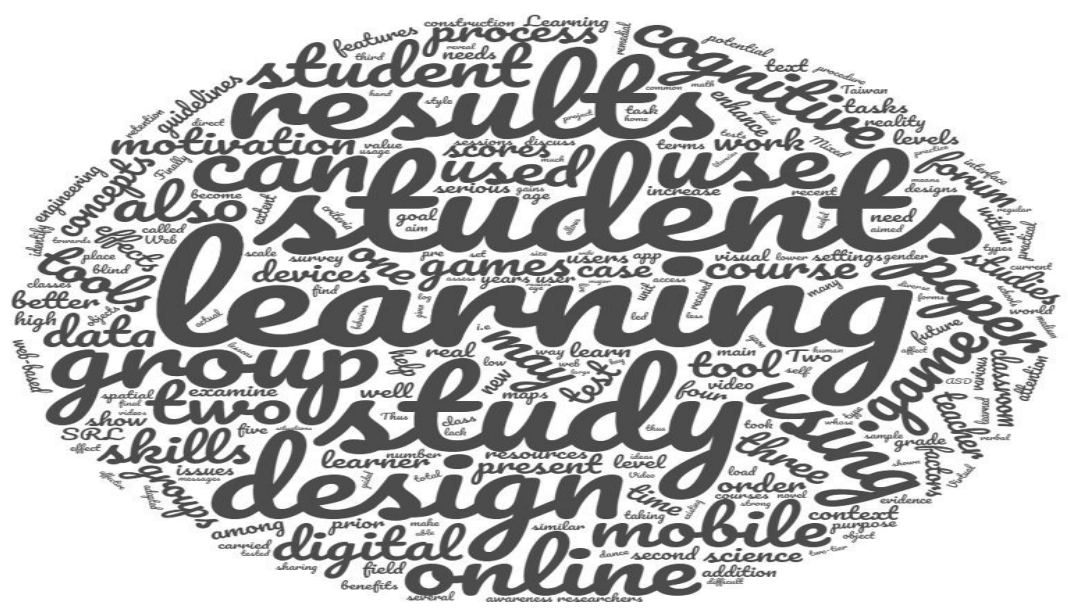

Fig. 3. Wordcloud analysis in ANS Research

\subsection{Learning process}

ANS influences the learning process carried out by students (distinguishes it from conventional one-for-all learning). It helps students organize previous knowledge required for current learning activities [9]. In addition, the kind of self-regulated learning allows students to do a learning exactly in what they want to know based on their learning progress [10]. They are able to learn from simple to more complex material gradually [11]. Moreover, there is an association between ANS-based learning with learning in groups which distinguish it from conventional one-for-all learning. In this context, a group of students can be used as a standard and basis to develop a more precise student's model within the group [6].

\subsection{Learning method}

Some literatures report the use of ANS in a mobile environment. By implementing ANS on a mobile platform, engagement from students on the courses they follow will increase. This is due to two things. First, mobile devices are now become the main tool for accessing information through the Internet. The educational institution should begin to embrace and integrate this technology into learning activities [12]. Second, mobile devices are very pervasive, the majority of students already have, use, and familiar with it. Although there are some limitations on using these devices, such as capacity, configuration, responses, and time constraint [13], mobile devices will raise the students' excitement in learning [14]. Mobile paradigm in learning is suitable for outdoor learning activities where students need to move from one place to another [9]. It allows students to keep engage with their course, doing their assignments, and reading some materials while they outside the class. ANS, in this regard, can provide the students a track of learning activities [13]. 


\subsection{Learning impact}

The adoption of ANS could raise positive effect on students' performance. The learning result coming from ANS system represents not only overall score but also the capability of students in organizing knowledge [15]. This is become an advantage of ANS over the conventional scoring system where all students receive same treatment from their teacher. In fact, it also can significantly increase the learning efficiency [16] and the students' scores [9]. Besides of the scores, the adaptive system motivates the students to learn better [17].

\section{Conclusion}

Adaptive Navigation Support can help students learning better by reducing cognitive load in navigating the system. Several researches is done in various contexts. Based on result, there are three dimensions of ANS usage in educational context, namely process, methodology, and impact. However, (1) most ANS are still applied to informatics courses, such as JAVA, XML. There have not been many studies that have explored the application of ANS on courses other than exact sciences, for example social sciences. (2) ANS research needs to be improved on mobile platforms, since mobile devices have become important tools for learning, at the same time, mobile platforms have a different design format than web or PC-based platforms.

\section{$5 \quad$ References}

[1] P. Brusilovsky, "Adaptive navigation support in educational hypermedia: the role of student knowledge level and the case for meta-adaptation," Br. J. Educ. Technol., vol. 34, no. 4, pp. 487-497, 2003. https://doi.org/10.1111/1467-8535.00345

[2] P. Brusilovsky, "Adaptive Navigation Support," in The Adaptive Web: Methods and Strategies of Web Personalization, P. Brusilovsky, A. Kobsa, and W. Nejdl, Eds. Berlin: Springer-Verlag Berlin Heidelberg, 2007, pp. 263-290. https://doi.org/10.1007/978-3-54072079-9

[3] A. Klašnja-Milićević, B. Vesin, M. Ivanović, and Z. Budimac, "E-Learning personalization based on hybrid recommendation strategy and learning style identification," Comput. Educ., vol. 56, no. 3, pp. 885-899, 2011. https://doi.org/10.1016/j.compedu.2010.11.001

[4] P. Brusilovsky, G. Chavan, and R. Farzan, "Social Adaptive Navigation Support for Open Corpus Electronic Textbooks," in Adaptive Hypermedia and Adaptive Web-Based Systems, P. De Bra and W. Nejdl, Eds. Springer-Verlag Berlin Heidelberg, 2004, pp. 24-33. https://doi.org/10.1007/978-3-540-27780-4 6

[5] S. Somyürek, "The new trends in adaptive educational hypermedia systems," Int. Rev. Res. Open Distance Learn., vol. 16, no. 1, pp. 221-241, 2015.

[6] F. Lazarinis, S. Green, and E. Pearson, "Creating personalized assessments based on learner knowledge and objectives in a hypermedia Web testing application," Comput. Educ., vol. 55, no. 4, pp. 1732-1743, 2010. https://doi.org/10.1016/j.compedu.2010.07.019

[7] N. Stanton, "Content analysis: A methodology for hypermedia design," 1995.

[8] Y. Zhang and B. M. Wildemuth, "Qualitative Analysis of Content," in Applications of Social Research Methods to Questions in Information and Library Science, B. M. Wildemuth, Ed. London: Libraries Unlimited, 2009, pp. 308-319. 
[9] C.-C. Chen and T.-C. Huang, "Learning in a u-Museum: Developing a context-aware ubiquitous learning environment," Comput. Educ., vol. 59, no. 3, pp. 873-883, 2012. https://doi.org/10.1016/j.compedu.2012.04.003

[10] M. C. Kim and M. J. Hannafin, "Scaffolding problem solving in technology-enhanced learning environments (TELEs): Bridging research and theory with practice," Comput. Educ., vol. 56, no. 2, pp. 403-417, 2011. https://doi.org/10.1016/j.compedu.2010.08.024

[11] K. Dolenc and B. Aberšek, "TECH8 intelligent and adaptive e-learning system: Integration into Technology and Science classrooms in lower secondary schools," Comput. Educ., vol. 82, pp. 354-365, 2015. https://doi.org/10.1016/j.compedu.2014.12.010

[12] M. A. Al Khateeb, "Effect of Mobile Gaming on Mathematical Achievement among 4th Graders.,” Int. J. Emerg. Technol. Learn., vol. 14, no. 7, 2019. https://doi.org/10.3991/ijet. $\underline{\mathrm{v} 14 \mathrm{i} 07.10315}$

[13] C.-K. Chiou, J. C. R. Tseng, G.-J. Hwang, and S. Heller, “An adaptive navigation support system for conducting context-aware ubiquitous learning in museums," Comput. Educ., vol. 55, no. 2, pp. 834-845, 2010. https://doi.org/10.1016/j.compedu.2010.03.015

[14] Á. Fernández-López, M. J. Rodríguez-Fórtiz, M. L. Rodríguez-Almendros, and M. J. Martínez-Segura, "Mobile learning technology based on iOS devices to support students with special education needs," Comput. Educ., vol. 61, pp. 77-90, 2013. https://doi.org/10. 1016/i.compedu.2012.09.014

[15] L.-H. Chen, "Enhancement of student learning performance using personalized diagnosis and remedial learning system," Comput. Educ., vol. 56, no. 1, pp. 289-299, 2011. https://doi.org/10.1016/j.compedu.2010.07.015

[16] H. Lin, S. Xie, Z. Xiao, X. Deng, and K. Cai, "Adaptive Recommender System for an Intelligent Classroom Teaching Model.," Int. J. Emerg. Technol. Learn., vol. 14, no. 5, 2019. https://doi.org/10.3991/ijet.v14i05.10251

[17] S. Narciss et al., "Exploring feedback and student characteristics relevant for personalizing feedback strategies," Comput. Educ., vol. 71, pp. 56-76, 2014. https://doi.org/10.1016/j. compedu.2013.09.011

\section{Authors}

Almed Hamzah is a researcher at Department of Informatics, Universitas Islam Indonesia. He is a member of Center of Study Enterprise Information System at Universitas Islam Indonesia. His researches are in fields of mobile learning, adaptive learning, and human computer interaction.

Kurniawan Dwi Irianto is pursuing his $\mathrm{PhD}$ at Deutsche Telekom Chair of Communication Network, TU Dresden, Germany. He obtained Bachelor Degree in Electronics Engineering from Universitas Muhammadiyah Surakarta (Indonesia) and Master Degree in Networks and Performance Engineering from University of Bradford (UK) in 2007 and 2013, respectively. His researches are in fields of wireless networks, cooperative communication, partial packets, digital network coding, physical-layer network coding, channel coding, web and mobile computing, and E-learning. He is affiliated with Universitas Islam Indonesia as junior lecturer as well as with IEEE as student member. Further info on his homepage: https://cn.ifn.et.tu-dresden.de/chair/staff/irianto/.

Article submitted 2019-04-22. Resubmitted 2019-06-11. Final acceptance 2019-06-12. Final version published as submitted by the authors 